\title{
Synchrotron beamlines open as plans are laid for repairs
}

Grenoble. Shutters are being opened this week to allow X-rays through for experiments at the European Synchrotron Radiation Facility (ESRF) here despite continuing problems with the ECU450 million (US\$600 million) facility's concrete floor. Later this month, officials are expected to approve rebuilding more than half of the floor, at a cost of ECU2 million, to correct the most serious problems with the least disruption to the scientific programme.

The two beamlines coming alive this week are for crystallography and work on tiny samples of rare materials or at high pressure, with a third, multipurpose beamline opening later this month. The lines will allow researchers to work with high brilliance, the facility's special feature, and to learn more about such technical problems as releasing large amounts of heat. Scientists also want to know whether the grouting injected into the floor underneath these beamlines will reduce vibration adequately. "We will be getting photons", says one scientist, "but whether we can handle them is another matter".

The trouble with the floor has its roots in a decision, made largely for reasons of politics and economics, to build the synchrotron at Grenoble rather than at a competing site at Strasbourg despite its being subject to seismic vibrations and city noises, its proximity to rivers and roads and its lying on postglacial alluvial terrain. Comparable machines rest on rock, with tidal movement in some cases being the only detectable vibration.

The problems were compounded during construction, starting in 1989 , by soil that was not compacted, concrete slabs that were too thin and surfaces that were worked prematurely. In addition, a steel reinforcement grid was laid below rather than within these slabs. "A supermarket floor", scoffs one scientist, referring to a type of project commonly handled by Bouygues, the large French civil engineering consortium that performed the work.

Voids below the surface began to appear in June 1991, followed by broken corners, disintegrating surfaces and misalignment of the concrete slabs. Walking on the edge of a slab was enough to cause a vibration 200 times greater than the highest levels acceptable. Last month, as part of litigation between Bouygues and ESFR, a French court appointed two experts to study the case and determine who should bear the cost of repairs.

On 24 November, the ESRF Council will hear recommendations from two advisory bodies that it should replace one major sector of the 250-metre-diameter floor while allowing experiments to continue on the opposite side. Under that plan, repairs would begin in spring 1993 and take 20 weeks, with the entire ring being shut for six or

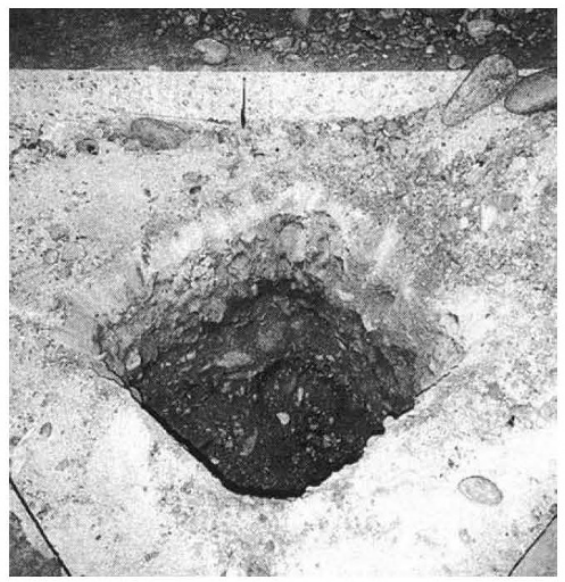

The alluvial terrain appears below the compacted grave, sand and concrete beneath the floor of the ESRF; a pen indicates the thickness of the slab.

seven weeks. The leading design, from engineers at Britain's Harwell Laboratory, would involve digging up the existing 15

$\mathrm{cm}$ concrete floor and installing a layer 70 to $80 \mathrm{~cm}$ thick. Workers compact the natural gravel bed first, and then put down thicker vibration-absorbing layers before laying concrete.

It is generally agreed that the problem cannot be eliminated because of constraints imposed by existing buildings, principally the ring. A better design would have been to put the whole installation on a single reinforced foundation rather than having the ring and experimental hall on separate concrete platforms.

The cost of repairs amounts to about 10 per cent of the facility's annual budget, and a significant part of the money available for research. Even so, the spirits of ESRF scientists have risen with the arrival of Yves Petroff, who in January succeeds Ruprecht Haensel as director-general. Outside research teams have been offered 48-hour slots for simple demonstration projects to run in parallel with the commissioning of the beams, and officials are confident that at least seven beamlines will be open to users by spring 1994 .

"People have been waiting a long time for a facility like this", says one scientist. "There is nothing else like it in the world."

Susan Biggin

\section{French modify polio plant in India}

New Delhi. A French vaccine manufacturer has agreed to retool a plant under construction outside Delhi to make the type of polio vaccine preferred by the Indian government. The decision reverses a position taken earlier this year (see Nature 356, 94; 1992) by the Institut Marieux that it would withdraw from the joint venture and stop work on the plant, expected to be ready by the end of the year. "We are putting good customer relations ahead of financial considerations", says a company spokesman in Delhi.

The change of heart appears to be the result of talks last month in Paris between science ministers of the two countries and the subsequent visit of the Indian prime minister, P.V. Narasimha Rao, to France. Rao was apparently able to convince the French president, Francois Mitterrand, that the company's withdrawal would jeopardize India's immunization efforts.

In 1989, the Institut Marieux joined with the Indian government to start building the biggest vaccine plant outside Europe for the manufacture of injectable polio vaccine. The company was persuaded to share its technology because of the large Indian market and the likelihood that other developing nations might also purchase the vaccine.

But the project ran into trouble last year when India, following the recommendation of a report by the World Health Organization, decided to use the cheaper oral polio vaccine instead of the injectable vaccine that Institut Marieux planned to make. The company said that it would pull out of the project until it was allowed to market the injectable vaccine to India, its only assured customer. Several rounds of talks ended in a deadlock last summer and in July the company's chief executive office, Alain Audubert, said that "we have decided to freeze all further commitments to the project".

That is no longer the case. Later this month, a committee of experts from Institut Marieux and the Indian Department of Biotechnology is expected to submit a report on ways to convert the manufacturing plant, and company officials say that they are already working "to make up for lost time". If all goes well, the first batch of vaccine could be ready by the middle of 1993 . K.S. Jayaraman 